\title{
Expression of Breast milk-an update
}

\author{
Khatoon $\mathrm{S}^{1}$, Begum $\mathrm{T}^{2}$, Begum $\mathrm{N}^{3}$
}

\begin{abstract}
Breast feeding by sucking is the norm. However sometimes expression is the only way by which breast milk can be given to babies. There are many situations when expressing breast milk is useful and necessary to enable a mother to initiate or to continue breast feeding. Hand or breast pump are used to express breast milk. Hand expression is the most preferred method. There are some mechanical pumps though pumps cause discomfort and are usually ineffective. The Marmet technique of expressing breast milk with hand is a fabulous alternative to using a breast pump. Until recently hand expression of breast milk has been as underutilized skill. However, there are many benefits of knowing how to express milk from the breast without the use of expensive and cumbersome breast pumps. Expressed breast milk can be feed by spoon, cup and nasogastric tube. It is essential to collect and store breast milk properly to prevent the risk of bacterial overgrowth. Feeding with breast milk is quite safe if done properly. It is important for every woman to learn to express the milk. Certainly all health workers who take care for breastfeeding mothers should be able to teach the way of expression of breast milk.
\end{abstract}

Key words: Breast milk, hand expression, breast pump

\section{Introduction}

Human milk is recognized as the optimal feeding for all infants because of its proven health benefits to infants and their mothers. Breastfeeding is one of the most beautiful and natural experiences a mother can share with her baby. Expression of breast milk is simply a way of taking milk from breast without suckling by the baby ${ }^{1}$. Breast feeding by sucking is the norm. But when infants are not able to suckle then expression is the only way by which breast milk can be given to babies and babies can get unique benefits of breast milk. But there are many other indicators for which expression are important ${ }^{1,2}$. Expressing milk is useful to feed a low birth weight and sick baby who cannot breastfeed. Expression is necessary to relieve engorgement and keep the supply of breast milk when mother goes out. Providing expressed breast milk offered one way the mothers could be physiologically and emotionally connected to her baby. The ability to express breast milk is invaluable in supporting and prolonging breastfeeding. So, there are many situations in which expressing breast milk is useful and important to enable a mother to initiate or to continue breast feeding. Some experts consider that all mothers should learn how to express their milk, so that they know what to do if the need arises ${ }^{3,4,5}$.

\section{Methods of breast milk expression}

Milk may be hand expressed or with a mechanical pump. Hand expression doesn't require equipment and involves manually removing milk from the breasts. Pumping and hand expression is a learned skill. A health care professional should be familiar with the technique of manual expression and be able to diagnose improper technique.

A. Hand or manual expression - The Marmet technique

B. Breast pump expression

A. Hand or manual expression: Hand expression is the most preferred method. A woman should express her own breast milk. It is more difficult when the breasts are engorged and tender. For this reason mothers should be taught about how to express her milk in the first or second day after delivery and not wait until the third day when her breasts are full. There are many advantages of manual expression over mechanical methods of milking the breast. Some mechanical pumps cause discomfort and are ineffective. Many mothers are more comfortable to manual expression and it is more natural. Skin to skin contact is more stimulating than the feel of a plastic shield. That's way manual expression usually allows an easier milk ejection reflex. It is convenient and ecologically superior. It is portable because hands are always

1. Prof. Soofia Khatoon, Professor \& Head, Department of Paediatrics, Shaheed Suhrawardy Medical College \& Hospital, Dhaka

2. Dr. Tamanna Begum, Associate Professor, Department of Paediatrics, Shaheed Suhrawardy Medical College \& Hospital, Dhaka

3. Dr. Nazma Begum, Assistant Professor, Department of Paediatrics, Shaheed Suhrawardy Medical College \& Hospital, Dhaka

\section{Correspondence}

Dr. Tamanna Begum, Associate Professor, Department of Pediatrics, Shaheed Suhrawardy Medical College \& Hospital, Dhaka, Bangladesh; E-mail: dr_tamanna@hotmail.com,dr_tbegum@yahoo.com; Cell No.: +8801711637371 
with the mother There is a less risk of cross infection ${ }^{1,6}$.The Marmet technique of manual expression has been developed by Chele Marmet who is the Director of the Lactation Institute in West Los Angles USA. This expression is sometimes called the letdown reflex which has worked for 100 of mothers ${ }^{7,8}$. To express milk effectively it is helpful to stimulate the oxytocin reflex and to use a good technique. Stimulating the oxytocin reflex is helpful with pump expression as well as with hand expression. Steps which will help to stimulate the oxytocin reflex are massage the milk producing cells and ducts, stroke the breast area from the top of the breast to the nipple with a light tickle like stroke, shake the breast while leaning forwards the gravity will help milk ejection.

\section{The Marmet Technique}

1. Compress the breast over ducts to put mothers thumb on breast above the areola and the first finger on the breast below the nipple and areola, opposite the thumb. Mother should supports the breast with the other fingers (Fig-1).

2. Press the thumb and first finger slightly inwards towards the chest wall.

3. Press the breast behind the nipple and areola between the fingers and thumb. Mother must press on the lactiferous sinuses beneath the areola.

4. Continue in a cycle of press and release \& them again press and release

5. This should not hurt. If it hurts then the technique will be wrong.

6. Express one breast for at least 3 to 5 minutes until the flow slows. Adequately expression of breast milk takes 20-30 minutes ${ }^{1,9}$ (Fig-1).

The entire procedure should take approximately 20 to 30 minutes. Express each breast 5 to 7 minutes ${ }^{2,3,4}$.

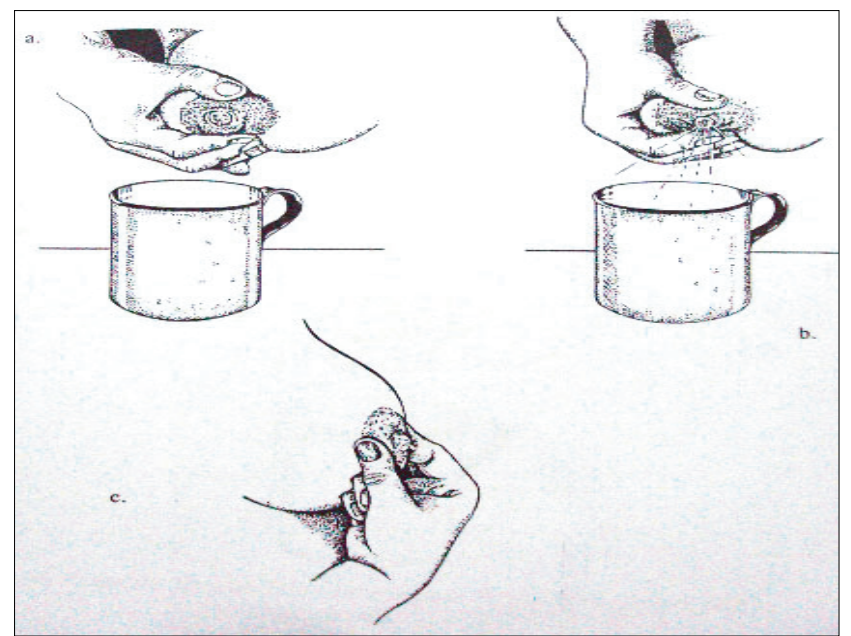

Figure I: Expressing the breast milk - procedure

B. Breast pumps: There are four types of breast pumps. These are a) Rubber bulb pump b) Electric breast pump c) Syringe pump d) Warm bottle methods. It is usually helpful to stimulate the oxytocin reflex before pumping by sitting comfortably with support for the back and the arm holding the pump ${ }^{3,5}$.

a) Rubber Bulb Pump: These are useful mainly to relieve engorgement when hand expression is difficult. That is why they are often called breast relievers (Fig-II). Disadvantage are not suitable for collecting milk to feed a baby because these are difficult to clean properly. These are not very efficient especially when the breasts are soft.

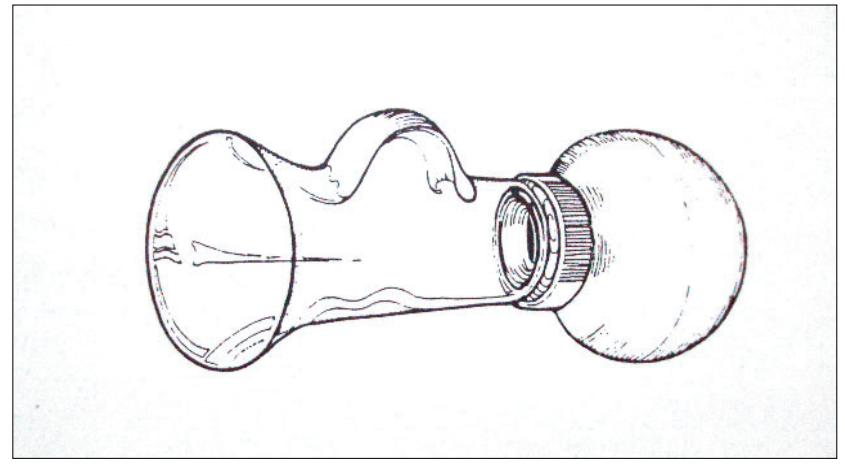

Figure II: Rubber pump

b) Electric Breast Pumps: These pumps are more efficient and suitable for use in hospitals. Automatically cycle suction with release of suction similar to a baby's sucking action. There are many good, mini-electric, battery-operated and hand breast pumps available in the market. Disadvantages: All breast pumps can easily carry infection. This is especially dangerous if more than one woman is using the same pump. These pumps were designed to obtain milk for an occasional relief not for long term milk expression. Mother needs to invest more time and effort to obtain an adequate amount of milk. Most of the breast pump becomes causes soreness or tenderness ${ }^{1.2 .4}$.

c) Syringe Pump: The syringe pump is made from a $50 \mathrm{ml}$ syringe. The nozzle part of the syringe is cut off then the plunger is taken out from back and refitted in the back part of the syringe. The smooth part of the syringe will fit over the nipple. This technique is useful for treatment of inverted nipple $^{1,3}$ (Fig-III). Advantage: A syringe pump is more efficient than a rubber bulb and it is easier to clean and sterilize.

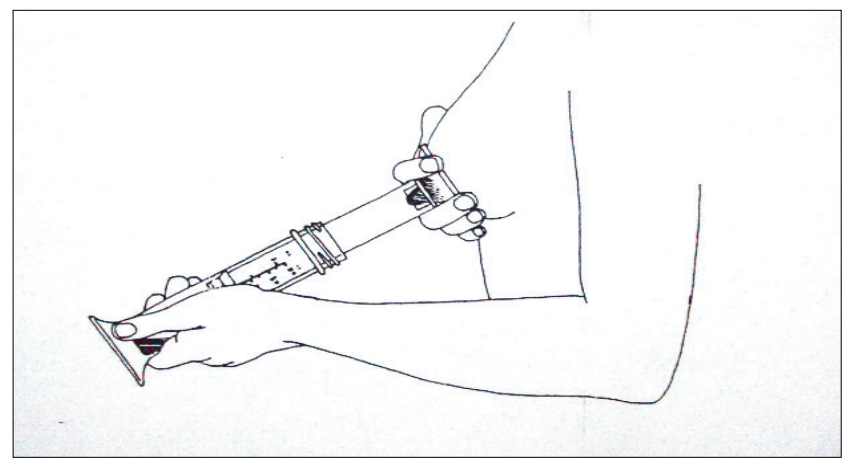

Figure III : Syringe pump 
d) The Warm Bottle Method: This is useful technique to relieve engorgement especially when the breast is very tender and the nipple is tight and hand expression is difficult. A wide necked (at least $2 \mathrm{~cm}$ diameter) glass bottle of 1 to 3 liter in size not smaller than $700 \mathrm{ml}$ is required and the followings are also required. A pan of hot water to warm the bottle and a thick cloth to hold the hot bottle ${ }^{4,6,7}$ (Fig-IV).

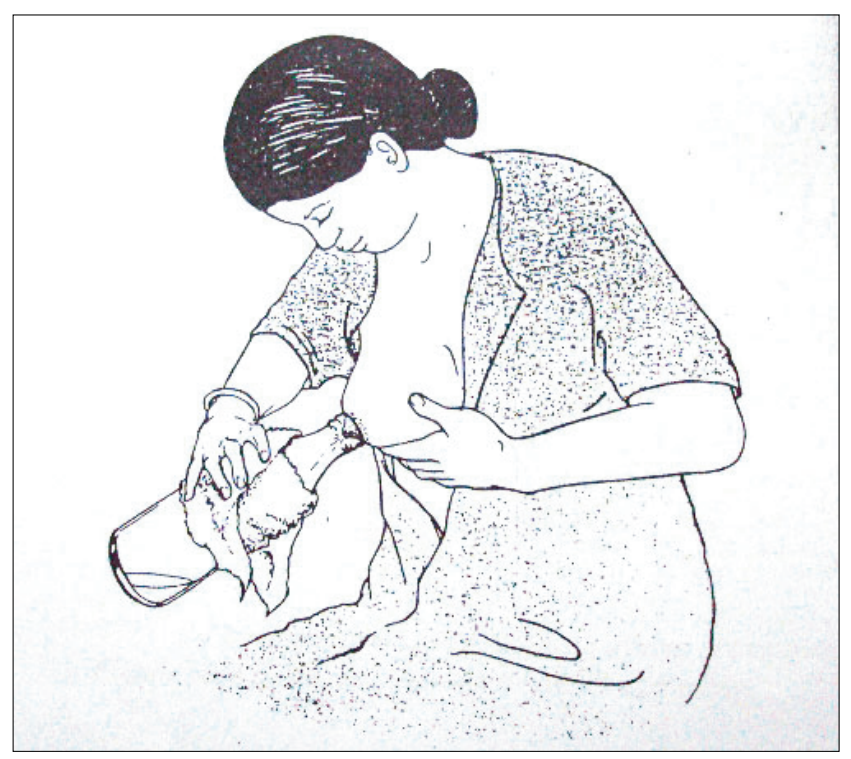

Figure IV: Warm bottle method

Storage of expressed breast milk (EBM): Immediately after expressing breast milk should be store into a clean container. EBM can be stored in a cool place for up to 8 hours and in a refrigerator for 24-48 hours ${ }^{3,10,11}$. Before using the breast milk, it should be returned to room temperature. If necessary the container can place with breast milk in a bowl of warm water. Breast milk should never be boiled or refreeze. Freshly expressed milk should not be added to previously stored milk $^{3,10,11}$.

\section{Conclusion}

Hand expression is the most useful way to express breast milk. It is less likely to carry infection than a pump and is available to every woman at any time. It is important for women to learn to express the milk by hand and not to think that a pump is necessary. Every woman should learn to express milk. It should know the freauency \& Duration of expression of breast milk.

\section{References}

1. F.Savage king. Helping Mothers to Breastfeed. Revised edition.1992; African Medical and Research Foundation, Nairobi, Kenya

2. Breast feeding counseling: A training course trainer's guide WHO, UNICEF 1993; 253-73

3. Hand- expression new beginnings, March-April 1996; 13(2): 512

4. Infant and young Child feeding Model chapter for text book for Medical student and allied of WHO, 2009

5. WHO. The Global burden of disease 2004 update. Geneva, 2008

6. Infant and young Child feeding Counseling: An Integrated Course. Participant's Manual. WHO 2006

7. Dadhch J P, Agarwal RK. Mainstreaming early and exclusive breast feeding for improving child survival, Indian Pediatrics 2009; 48: 11-17

8. Talukder M Q K, Das DK, Selta GE, Infant Feeding practices in rural Bangladesh. Indian J Pediatr 1992; 59: 573-77

9. Giashuddin MS, Kabir M. Duration of breast-feeding in Bangladesh. Indian J Med Res 2004;119:103-05

10. Shaha KK, Frongillo E, Alam D S, Arefeen SE, Persson LA, Rasmussan KM. Appropriate infant feeding practices result in better growth of infants and young children in rural Bangladesh. American J Clinical Nutrition 2008;87:852-59

11. Ludvigsson JF. Breast feeding initiation, pattern, and determinants visiting in hospitals in Paz, Bolivia. BMC Pediatrics 2003; 115: 1-15. 